\title{
Gad c 1 efficiency in the diagnosis of fish allergy in children
}

\author{
O Domínguez ${ }^{1 *}$, P Carrillo², M Giner ${ }^{1}$, M Piquer ${ }^{1}$, M Alvaro $^{1}$, R Jimenez-Feijoo ${ }^{1}$, J Lozano ${ }^{1}$, M Pascal ${ }^{3}$, A Plaza ${ }^{1}$ \\ From Food Allergy and Anaphylaxis Meeting (FAAM 2013) \\ Nice, France. 7-9 February 2013
}

\section{Background}

Fish is one of the main culprit foods in childhood allergy [prevalence below 5 years $30 \%$ and then $9.8 \%$, Spain]. IgE-mediated fish allergy diagnosis (FAD) is based on specific IgE (sIgE) detection to fish whole extracts and parvalbumin, considered to be major allergen, despite oral challenge $(\mathrm{OC})$ is still the gold standard. Parvalbumin is an important panallergen. Cod parvalbumin ( $\mathrm{Gad} \mathrm{c} 1)$ is used for FAD in general; however its efficiency in FAD to species other than cod has not been reported. We sought to evaluate Gad c1 efficiency in FAD.

\section{Methods}

Medical records of children screened and followed for suspected fish allergy from 2009 to 2012 were reviewed looking for clinical data, sensitization to frequent fish species (cod, hake, sole; monkfish, tuna, swordfish, sardine) and Gad c 1, and OC outcome. Descriptive statistics and Gad c 1 efficiency was reported. Patients were grouped: A $($ Gad c $1+)$ and B (-).

\section{Results}

Data of 58 children (median[range] age: 7 [4-17]; 57.6\% boys) was collected. $75.8 \%$ had multiple food allergy, $69.5 \%$ respiratory and $38 \%$ atopic dermatitis (AD). 9 (15\%) had Gad c 1 sensitization. Regarding symptoms at diagnosis: anaphylaxis (An, 28\%) [hake (34\%)/sole (15\%)], urticaria $(24 \%)$ and $\mathrm{AD}(12 \%) .41 \%$ have had symptoms in several episodes and different species. 5 (10\%) had symptoms by inhalation. 40 (69\%) belonged to $\mathrm{A}$ and 18 to $\mathrm{B}$. OC data about 22 of A showed: for blue fish, tuna was usually the first one challenged and the most frequently tolerated $(\mathrm{T})$ [canned $(\mathrm{C}, \mathrm{n}=19: 18 \mathrm{~T} / 1 \mathrm{An})$ and fresh $(\mathrm{F}$, $\mathrm{n}=11,9 \mathrm{~T})$ ]. For swordfish $(\mathrm{n}=8: 7 \mathrm{~T} / 1 \mathrm{An})$ and sardine was tried in 1 causing An. For white fish, hake was the most frequent OC $(n=4: 1 \mathrm{~T} / 3 \mathrm{An})$. For sole $(\mathrm{n}=3: 1 \mathrm{~T})$, monkfish ( $\mathrm{n}=3,3 \mathrm{An})$ and cod was tried in 1 patient causing An. In B, OC data was available on 7 children (39\%) and tolerance rate was globally higher than $\mathrm{A}$. For blue fish, tuna $(F / C, n=3)$ all tolerated, swordfish $(n=0)$ and sardine $(n=1, T)$. For white fish, hake was the most frequently used for OC $(\mathrm{n}=6$, all $\mathrm{T})$. For sole $(\mathrm{n}=5,4 \mathrm{~T})$ and monkfish $(\mathrm{n}=5$, all $\mathrm{T})$. Cod was tried in none. Gad c 1 efficiency was for: hake (90\%), sole (75\%), tuna (36\% F/18\% C). Efficiency for swordfish, sardine, monkfish and cod could not be evaluated because of too small sample size.

\section{Conclusion}

Hake and sole were the most frequent offending species. Most children present anaphylaxis and urticaria (at diagnosis and OC outcome). Despite Gad c 1 is used for routine FAD, it seems to be more efficient in white fish allergy than blue fish.

\section{Disclosure of interest}

None declared.

\section{Author details}

${ }^{1}$ Allergy and Clinical Immunology Department, Hospital Sant Joan de Deu, Barcelona, Spain. ${ }^{2}$ Allergy Department, Hospital Virgen Arrixaca, Murcia, Spain. ${ }^{3}$ Immunology Department, CDB. Hospital Clinic, Barcelona, Spain.

Published: 25 July 2013

\section{doi:10.1186/2045-7022-3-S3-P54}

Cite this article as: Domínguez et al:: Gad c 1 efficiency in the diagnosis of fish allergy in children. Clinical and Translational Allergy 20133 (Suppl 3):P54. 